\title{
El pathos de la vida y de la existencia. La fenomenología en busca de una ampliación de la razón ${ }^{1}$
}

\author{
Patricio Mena Malet ${ }^{2}$
}

Recibido: 29 de junio de 2017 / Aceptado: 03 de abril de 2018

Resumen. El presente artículo busca interrogar el pathos de la vida y de la existencia, a partir del estudio de las obras de Michel Henry y de Henri Maldiney. Dicho intento de ampliar la razón recobrando la dimensión afectiva de la vida (Henry) o de la existencia (Maldiney) ha orientado a la fenomenología hacia una reflexión profunda sobre una inmanencia absoluta de la vida o sobre la apertura hacia el acontecimiento de sentido que es propia a la existencia. De este modo, nos pregunatremos qué fenomenología (Henry o Maldiney) se apropia mejor la tarea de ampliar la razón hacia la dimensión del sentir y de la afectividad.

Palabras claves: Henry; Maldiney; pathos; fenómeno; existencia; vida.

\section{[en] The pathos of life and existence. Phenomenology in search of an extension of reason}

Abstract. This article aims to interrogate the pathos of life and existence, from the study of the works of Michel Henry and Henri Maldiney. This attempt to extend reason by recapturing the affective dimension of life (Henry) or existence (Maldiney) has guided phenomenology to a reflection on the absolute immanence or on the opening towards the event of meaning proper to existence. In this way, we will ask ourselves what phenomenology (Henry or Maldiney) is better appropriated the task of extending the reason to the dimension of feeling and affectivity.

Key words: Henry; Maldiney; pathos; phenomenon; existence; life.

Sumario: 1. Introducción: el fenómeno en cuestión y las exigencias de ampliación de la razón; 2. La patética de la vida; 3 . Lo páthico de la existencia; 4 . La acontecialidad y el encuentro que exponen el dónde de la manifestación; 5 . Referencias bibliográficas.

Cómo citar: Mena Malet, P. (2019): "El pathos de la vida y de la existencia. La fenomenología en busca de una ampliación de la razón", en Revista Anales del Seminario de Historia de la Filosofía 36 (1), 201-220.

1 Este texto se ha escrito en el marco del proyecto EXS 16-0204 de la Universidad de La Frontera. También es parte del trabajo de preparación del Proyecto Fondecyt Regular $\mathrm{N}^{\circ} 1180375$, del que el autor es Investigador Responsable.

2 Universidad de La Frontera, Temuco, Chile patricio.mena.m@ufrontera.cl ORCID: https://orcid.org/0000-0001-5936-8641 


\section{Introducción: el fenómeno en cuestión y las exigencias de ampliación de la razón}

En el prólogo de Au coeur de la raison: la phénoménologie, Claude Romano afirma que: "Si hay algo que Husserl nos ha enseñado, es que el método en la filosofía no es importado desde el exterior, que no consiste en un conjunto de preceptos vacíos dictados abstractamente, es decir, independientemente de los objetos sobre los cuales trata esta disciplina, puesto que el método es uno con la marcha filosófica misma y con la 'cosa', el 'asunto' (Sache) a la que éste tiene por finalidad reconducirnos"3. Por ello, la fenomenología, en tanto que método que tiene por función permitirnos un retorno "a las cosas mismas" (zu den Sachen selbst), esto es a las cosas tomadas conforme al cómo de su aparición, no puede avanzar sin aportar una comprensión del "fenómeno en sentido fenomenológico"s. Bien es sabido que el propio Husserl no abandona la tarea de pensar y precisar qué es la cosa en tanto que phainomenon. Así, desde una fenomenología pura o psicología fenomenológica -concentrada en la descripción de las vivencias de conciencia en su relación intencional con el objeto, y aún en el marco de una reflexión natural-, pasando por una fenomenología trascendental -que a través de la adopción de la actitud trascendental nos permite acceder al fenómeno reducido al puro aparecer, como unidad de sentido o como un vivir puro- hasta una filosofia fenomenológica trascendental que desemboca en un idealismo trascendental, tal como el defendido en las Meditaciones cartesianas -según el cual, el fenómeno es una unidad de sentido consituido por una instancia trascendental absoluta como lo es la conciencia-, Husserl no deja de interrogar lo que es fenómeno, siendo que su comprensión -que no es unívoca a lo largo de su marcha filosófica- depende y "sigue siendo tributaria de la reflexión metodológica" 6 requerida siempre por la fenomenología en tanto que tal. Así, en palabras de Perreau: "Toda la apuesta de esta definición -a saber, de lo que es fenómeno- es asegurar un dominio de objeto original que hace de la conciencia intencional el lugar propio de los fenómenos y hace de esta manera posible a la fenomenología como 'ciencia' de los fenómenos. La reflexión conducida sobre el fenómeno -continúa el autordebe permitir liberar la dimensión de lo fenomenológico, aquella de un discurso que describirá las estructuras esenciales de los fenómenos, es decir, de las vivencias de conciencia"?.

La consigna husserliana de volver "a las cosas mismas" implica entonces una interrogación continua tanto respecto de cómo volverse hacia los fenómenos, así como también de qué modo es preciso definir o comprender lo que es un fenómeno en el sentido aquí en juego ${ }^{8}$. Las razones de dicho retorno interrogativo continuo,

\footnotetext{
Romano, Claude. Au coeur de la raison: la phénoménologie. París: Gallimard, 2010, p. 17.

Husserl, Edmund. Investigaciones lógicas tomo II. Madrid: Alianza Editorial, 1985, p. 218.

Perreau, Laurent. "Le sens de l'apparaître. Le phénomène et le phénoménologique chez Husserl”. En: Perreau, Laurent (ed.). Le phénomène. París: Vrin, 2014, p. 160. Con respecto al fenómeno en sentido fenomenológico, Cfr. Benoist, Jocelyn. Logique du phénomène. París: Hermann, 2016, pp. 135-164; Depraz, Natalie Le phénomène. París: Bréal, 2014, pp. 93-131; Schnell, Alexander. Qu'est-ce que le phénomène. París: Vrin, 2014, pp. 53-78.

Perreau, Laurent, op. cit., p. 162.

Idem.

8 Esto en cuanto la noción de fenómeno tiene una larga historia previa a su consideración en la fenomenología husserliana, y que puede retrotraerse, en el campo de la filosofía, desde filósofos presocráticos como Anaxágoras, pasando por Platón, Aristóteles, los filósofos post-aristótelicos como los epicúreos, filósofos modernos como
} 
ciertamente, son múltiples, pero al menos se pueden destacar las siguientes, conforme a los fines que aquí nos interesan. En primer lugar, aquello que se nombra cuando se habla de fenomenología, a partir de Husserl en adelante, no es tan solo que ésta es una ciencia, la ciencia de los fenómenos, i.e. de las cosas tomadas en su aparecer a la conciencia o a la experiencia y, por lo tanto, del vínculo constitutivo que existe entre el sujeto y el objeto conforme al a priori correlacional de la intencionalidad, sino que también se deja comprender que es posible abocarnos a la tarea de la descripción de los fenómenos porque ellos, por muy mudos que sean, por mucho que se mantengan en las sombras de nuestra experiencia cotidiana en actitud natural, pueden, precisamente, ser dichos, expresados y, por tanto, descritos. Es, por ejemplo, lo que afirma Paul Ricoeur cuando dice que: "La fenomenología apuesta por una reflexión que sea implícitamente un 'decir', un légein; si la posibilidad de decir no estuviese inscrita en el 'querer decir' de la vivencia, la fenomenología no sería el lógos de los phainómena". La posibilidad de decir los fenómenos es, al mismo tiempo, la de promover un ensanchamiento de la experiencia que, en cuanto se tiene en la espontaneidad de la vida cotidiana, se mantiene ciega, porque ingenua y crédula, ante las cosas tomadas o reducidas al aparecer puro; así, una experiencia ensanchada es aquella que haciéndose, esto es, que llevando a cabo procedimientos tales como la epojé, la reducción fenomenológica o trascendental, busca darnos aquello que no nos es dado en la experiencia que cotidianamente tenemos, a saber, los fenómenos mismos. De esta manera, y en palabras de Alexander Schnell: "el fenómeno no es por tanto algo dado inmediatamente, puesto que 'no aparece' sino a través de una mediación. Esta mediación exige que no nos mantengamos al nivel de esas 'apariciones' inmediatas, sino que descendamos hacia las capas ultimamente constitutivas de estas últimas. El fenómeno, para Husserl, es así el conjunto de las estructuras intencionales y pre-intencionales (Husserl dice: 'pre-fenomenales') que caracterizan las efectuaciones propias de la subjetividad trascendental [...]. Dicho de otro modo, los fenómenos designan toda operación o función intencional (y preintencional) de la subjetividad, constitutiva de una donación de sentido"10.

A partir de aquí se puede comprender cómo el carácter metódico de la fenomenología -que busca ir "a las cosas mismas"- no puede ser tomado independientemente de la pregunta por el fenómeno y la fenomenicidad. Y es este lazo estricto entre uno y otro -entre método y fenómeno- lo que asegura la enorme flexibilidad de la fenomenología que sin abandonar la "expresión sistemática de una atención innovadora, rigurosa y perfectible a lo real" ", se entrega a la tarea de pensarse en conformidad a cada fenómeno que se busca interrogar: la carne (Merleau-Ponty), el rostro (Levinas), la vida (Henry), el existir (Maldiney), etc.; fenómenos que exigen a la fenomenología tener que repensar lo que es aparecer junto con sus modos de dilucidación. No se trata de una cuestión baladí. Pues, precisamente, buena parte de la recepción en Francia de la fenomenología husserliana -y heideggeriana- depende

Kant, Schopenhauer, Nietzsche, Hegel, hasta Husserl y Heidegger y las fenomenologías post-husserlianas y post-heideggerianas, sin que esta lista sea en nada exhaustiva. Para una revisión histórica de la noción de fenómeno en la historia de la filosofía, Cfr. Benoist, Jocelyn, op. cit.; Depraz, Natalie, op. cit. Le phénomène; Schnell, Alexander, op. cit.

9 Ricoeur, Paul. À l'école de la phénoménologie. París: Vrin, 1986, p. 69.

10 Schnell, Alexander, op. cit., p. 55.

11 Capelle-Dumont, Philippe. “Après Merleau-Ponty, que devient la phénoménologie française?”. En: Zarka, Yves Charles (ed.). La philosophie en France aujourd'hui. París: PUF, 2015, p. 189. 
de un gesto de renovación y de radicalización que bien lo expresa Michel Henry en la introducción de su Phénoménologie materielle: "La renovación de la fenomenlogía no es posible hoy en día más que bajo una condición -a condición que la cuestión que la determina enteramente, y que es la razón de ser de la filosofía, sea ella misma renovada. No corregida, ni enmendada, aún menos abandonada por otra, sino que radicalizada" ${ }^{\prime 2}$. Y esto, en tanto que la fenomenología se ha dado por tarea proponer una ampliación de la razón, una "nueva imagen de la razón"', una "razón extendida hasta incluir su otro, la sensibilidad, la experiencia, lo antepredicativo, una razón de gran corazón que rehabilite el mundo sensible como necesario para su existencia" 14 . Esto conducirá a Henry, por ejemplo, hacia una fenomenología de la vida presente a sí en una inmanencia absoluta. Mas, aquella razón extendida que requiere una renovación y una reconducción radical de la fenomenología ha sido también la labor de la fenomenología en su "momento francés" 15 - como lo indica Marion-, o de la "nueva fenomenología en Francia"16 -al decir de Gondek y Tengelyi-, que se ha detenido a pensar al fenómeno como "acontecimiento de sentido" (Sinnereignisse) ${ }^{17}$ o, dicho en otros términos, a lo dado en su "carácter acontecial"18. Es el caso de las fenomenologías de Maldiney, Marion, Romano, entre otros. Se trata para ellos de exponer la "fenomenalidad en su límite, la fenomenología en su imposibilidad" De este modo, se ha buscado pensar al fenómeno "bajo ninguna condición de posibilidad a priori [...], liberado de toda legalidad a priori $\mathrm{y}$, claramente, del gobierno de la conciencia"20. La radicalización de la fenomenología -abogada por Michel Henry, mas también por estos otros autores- toma forma destituyendo los prestigios del ego constituyente, problematizando -argumentando para conservar o abandonando de modo definitivo- la reducción trascendental ${ }^{21} \mathrm{y}$, con ello, el giro idealista de la fenomenología 22 ; abocándose así a la tarea de pensar al fenómeno en tanto que dado en sí y por sí como un acontecimiento de sentido, como Ereignis, lo que a su vez implica, a juicio de Marion por ejemplo, una recomprensión del mundo: "Desde entonces -afirma Marion- los pensamientos del mundo (en ciencias como en filosofía) lo definen a partir del tiempo como un acontecimiento, un posible, o incluso la posibilidad del advenimiento: el mundo como lo que adviene, ni cuantificable, ni totalizable, ni previsible, ni repetible. El tiempo ha sustituido al espacio, por tanto,

\footnotetext{
12 Henry, Michel. Phénoménologie materielle. París: PUF, 1990, p. 6.

13 Romano, Claude. Au coeur de la raison: la phénoménologie, op. cit., p. 15.

14 Ibid., p. 14.

15 Marion, Jean-Luc. "Un moment français de la phénoménologie". En: Rue Descartes, Phénoménologies françaises, (2002/35), pp. 9-13.

16 Cfr. Gondek Hans-Dieter \& Tengelyi, László. Neue Phänomenologie in Frankreich. Berlin: Suhrkamp, 2011. Respecto de las respuestas de algunos de los fenomenólogos franceses que han sido estudiados en esta obra, Cfr. Sommer, Christian (ed.). Nouvelles phénoménologies en France. París: Hermann, 2014.

17 Cfr. Serban, Claudia. 'La 'Nouvelle phénoménologie en France' et les événements de sens (Sinnereignisse). Un prologement de la lectura de László Tengelyi”. En: Cabestan, Philippe. Claude Romano. La raison et l'événement. París: Le Cercle Herméneutique, 2016, pp. 31-45.

18 Gondek Hans-Dieter \& Tengelyi, op. cit., p. 672.

19 Sebbah, Fraçois-David. "Nouvelle phénoménologie et post-phénoménologie". En: Sommer, Christian (ed.), op. cit., p. 150.

20 Ibid.

${ }^{21}$ Así por ejemplo, mientras que Jean-Luc Marion aboga aún por la reducción trascendental, Claude Romano la ha abandonado de modo definitivo sin dejar de inscribir su trabajo en la fenomenología.

22 Sobre la relación entre el giro idealista de la fenomenología y la reducción trascendental, Cfr. Mena, Patricio. "El fenómeno de la apelación”. En: Revista Co-herencia, (23), 2015, pp. 106-137.
} 
por una inversión prodigiosa: el tiempo, el sentido interno según Kant, abre el mundo más de lo que lo hace el sentido externo, es decir, el espacio"23.

Pensar, entonces, al fenómeno en su "carácter acontecial" 24 , en su advenir, es, a su vez, abocarse a la tarea de pensar al sujeto capaz de hacer la experiencia del advenimiento de sí a partir del arribo de lo que ha sido liberado de toda condición a priori de manifestación y, por consiguiente, a contrapelo de la vía intencional estudiada por Husserl. El sujeto, entonces, es aquel que hace la experiencia del fenómeno insigne que adviene por sus propios medios, que no se inscribe en un contexto de manifestación previo y delimitante, tal como el fenómeno saturado ${ }^{25}$ a juicio de Marion, y que adviniendo ofusca nuestra comprensión de sí, o, el acontecimiento que para Romano es el fenómeno que cumple con las exigencias de "mostrarse él mismo a partir de sí" ${ }^{26}$. Así las cosas, el lenguaje de la egoidad no puede aportarnos los recursos necesarios para comprender el tipo de sujeto comprometido ante el arribo de los fenómenos insignes; en vez de ego constituyente, se hablará mejor de adonado (Marion), adviniente (Romano), respondiente (Chrétien) o existente (Maldiney). Y ello, con el fin de dar mejor cuenta de la dimensión páthica que es constitutiva del sujeto expuesto al advenir mismo de aquellos fenómenos insignes. He aquí, precisamente y tras este largo rodeo, que se puede hallar en las obras de al menos dos autores franceses, tales como Michel Henry y Henri Maldiney $^{27}$, que, sin leerse mutuamente, van a poner en cuestión el privilegio de la intencionalidad - tan celebrado por autores como Sartre, Merleau-Ponty y Ricoeurpara, de forma distinta, acceder a aquella dimensión páthica (Maldiney) o patética (Henry) que viene, precisamente, a cumplir el programa propio de la fenomenología de abandonar, en palabras de Husserl, aquella "razón perezosa que rehúye la lucha a favor de la claridad de lo pre-dado último y la de los fines y los caminos verdadera y racionalmente predelineados" 28 . Examinemos entonces, a partir de las fenomenologías de Henry y de Maldiney, de qué modo estos autores intentan llevar a cumplimiento esta exigencia fenomenológica de extender la razón por medio de la rehabilitación del sentir y una crítica a la intencionalidad como vía de acceso a la dimensión pathica o patética de la existencia o la vida. Esto, eso sí, con la

23 Marion, Jean-Luc. “Jean-Luc Marion. Entretien avec Paul Audi”. En: Zarka, Yves Charles (ed.). op. cit., p. 468.

24 Cfr. Romano, Claude. L'événement et le monde. París: PUF, 1998, y del mismo autor, L'événement et le temps. París: PUF, 1999. Ambas obras de Romano intentan llevar a cabo una hermenéutica acontecial, siendo entonces que el fenómeno insigne es, a juicio del autor, el acontecimiento. Respecto de esto último, Cf. Vallé, MarcAntoine. "Par-delà le príncipe de raison: la phénoménologie de l'événement chez Jean-Luc Marion et Claude Romano". En: Cabestan, Philippe (ed.)., op. cit, pp. 17-29. Así también se pueden destacar los últimos trabajos de Renaud Barbaras que, a partir de su fenomenología de la vida y de dinámica de la manifestación piensa lo que él llama "archiacontecimiento" que define como "la única manera de no ser nada sin ser nada, a saber un puro advenir tan indeterminado que es imprevisible y único" (Barbaras, Renaud. Métaphysique du sentiment. París: Cerf, 2016, pp. 102-103. En adelante: MS). Sobre las nociones de acontecimiento en Romano y Barbaras, Cfr. Serban, Claudia, art. cit. En la fenomenología alemana se puede destacar a Bernhard Waldenfels -próximo en sus tesis a Maldiney, aunque sin que haya sufrido influencia alguna al respecto- y a Hermann Schmitz, recientemente traducido al francés. Cfr. Schmitz, Hermann. Brève introduction à la nouvelle phénoménologie. París: Le Cercle Herméneutique, 2016; Waldenfels, Bernhard. Exploraciones fenomenológicas acerca de lo extraño. Madrid: Anthropos / Siglo XXI editores, 2015.

25 Cfr. Marion, Jean-Luc. Étant donné. París: PUF, 2005, p. 314.

26 Romano, Claude. L'événement et le monde. París: PUF, 1998, p. 41.

27 Renaud Barbaras también propone, particularmente en su último libro, un retorno al sentir y al sentimiento. Cfr. $M S$.

28 Husserl, Edmund. La crisis de las ciencias europeas y la fenomenología trascendental. Buenos Aires: Prometeo, 2008, p. 60. 
siguiente precaución. Pues, si incluimos a Henry en este análisis es en razón de estos dos motivos recien nombrados; mas, es necesario reconocer que el autor no es del todo sensible a la dimensión acontecial del fenómeno, tal como sí aquellos que son hoy representantes de la nueva fenomenología en Francia. Mas, aún así, se deja inscribir en este nuevo paranomara de la fenomenología en tanto que también está tras un fenómeno insigne que no se deje constituir por la subjetividad, sino que, por el contrario, sea él condición de aquella.

\section{La patética de la vida}

Antes de comprometernos en el examen del pathos y de su relación con el fenómeno a partir de Henri Maldiney, quisiera insistir en la proximidad, pero, y sobre todo, en la distancia que hay entre Michel Henry y Henri Maldiney. Si bien es cierto que ambos llevan a cabo una fenomenología de la afección, del afecto o del sentir, y si también es cierto que ambos tienen una relación crítica y fundante con el parágrafo 85 de Ideas I, titulado "Hylé sensual, morphé intencional"29, cada uno de estos autores, sin embargo, se separa radicalmente del otro. En primer lugar examinemos algunas de las tesis principales de Henry, para luego, en el próximo apartado volver sobre la obra de Maldiney.

A Michel Henry le parece que la fenomenología noética husserliana terminó finalmente por recubrir la fenomenología hylética que a juicio de nuestro autor es el lugar a partir del cual llevar a cabo la ampliación de la razón. Así puede afirmar que: "Vuelta principio y único criterio de la fenomenalidad, acaparando el aparecer y reduciéndolo a su ver, la intencionalidad no se mantiene en tanto que ella misma: en tanto que hacer-ver, ella se arroja hacia lo que es visto, y eso, en una inmediación tal que su ver ya no es nada más, en realidad, que el ser-visto de lo que es visto, el objeto noemático cuyo estatuto fenomenológico es definido por su condición de objeto y se agota en ella: en el hecho de ser planteado ahí ante la mirada. El aparecer ya no es nada más que eso, el aparecer cuya fenomenalidad es ese Adelante como tal, la exterioridad pura, el aparecer que es el aparecer del ente" ${ }^{30}$. De este modo, la intencionalidad es ciega a sí misma y se halla impedida de revelar su propia revelación puesto que en tanto que hacer-ver se halla arrojada y perdida en lo visto ${ }^{31}$. No queda nada del entusiasmo que despertó la intencionalidad en la primera generación de fenomenólogos franceses; tampoco se halla en la obra de Henry ningún aprecio por la cuestión del ser, caída en el olvido según Heidegger, puesto que la fenomenología ha desterrado a su juicio, desde Husserl, a la ontología "considerada como disciplina

29 Husserl, Edmund. Ideas relativas a una fenomenología pura y una filosofía fenomenológica, Libro primero: Introducción general a la fenomenología pura. México: UNAM / FCE, 2013, pp. 281-286.

30 Henry, Michel. Phénoménologie de la vie I. De la phénoménologie. París: PUF, 2003, p. 110. En adelante: PhV 1.

31 Al respecto Henry afirma lo siguiente: "No se puede olvidar sin embargo la definición esencial de la conciencia como intencionalidad. Comprendida como intencional, la conciencia no es nada más el movimiento por el cual se arroja afuera, su 'substancia' se agota en esta ida afuera que produce la fenomenalidad. Revelar en una tal ir afuera, en una puesta a distancia, es hacer-ver. La posibilidad de la visión reside en esta puesta a distancia de lo que es planteado ante el ver y así visto por él. Tal es la definición fenomenológica del objeto: lo que, planteado delante, se ha vuelto visible de este modo. El aparecer es aquí el aparecer del objeto en un doble sentido: en el sentido que lo que aparece es el objeto, en el sentido también que lo que aparece siendo el objeto, el modo de aparecer aquí en cuestión es el modo de aparecer propio del objeto y que lo vuelve visible" (PhV 1, p. 61). 
segunda" ${ }^{32}$. Así, el asunto mismo de la fenomenología no es el ser, ni la existencia, sino el aparecer. La intencionalidad responde a ese problema siendo ella misma el "aparecer del ente según sus diversas modalidades"33.

Mas, entonces, si la intencionalidad, en tanto que hacer-ver, revela el aparecer del ente, ¿cuál es el aparecer propio de la intencionalidad? Esto es, ¿qué aparecer revela a la intencionalidad en tanto que operante ${ }^{34}$ No parece posible responder a esa pregunta si solo se toman en cuenta los recursos de la fenomenología husserliana, siendo que el "ver nunca es visto, la intencionalidad nunca es su propio objeto" ${ }^{35}$. Pero esto significa además que la intencionalidad debe tener otro fundamento que ella misma, el cual no parece ser por consiguiente intencional; en suma, la intencionalidad no puede darse elle misma a sí misma de modo intencional ${ }^{36}$; o, de otro modo dicho, no es posible un acceso a la conciencia intencional mediante la intencionalidad, sino que por una conciencia no-intencional ${ }^{37}$. Se reconoce, entonces, que la crítica a la intencionalidad va aparejada, a su vez, con la exigencia explícita de dar cuenta de lo que Henry llama el "aparecer original" que no es sino un "auto-aparecer", es decir, "un aparecer en el cual es el aparecer mismo que aparece, siendo entendido que es ese aparecer como tal que produce su auto-aparecer"38. La fenomenología, por tanto, se ha vuelto con Henry un análisis o descripción del puro aparecer tomado éste en una suerte de autonomía respecto de lo apareciente, como si fuera posible-Henry lo cree ciertamente- dilucidar el aparecer de modo independiente de sus apariciones. "Desligado de todo fenómeno singular, afirma Bégout, la fenomenalización misma pierde su substancia fenomenal" 39 . Así las cosas, la fenomenología se comprende a sí misma, según Bégout, como una fenología pura, i.e., un estudio concentrado solo en el phainesthai sin consideración de los phainomena ${ }^{40}$, y todo ello en busca de un Urphänomen que para Henry será la vida en tanto que auto-aparecer, automanifestación o Archi-Revelación que constituye "el auto-aparecer del aparecer"41, es decir, la "fenomenalidad pura de este aparecer" de lo que aparece, sino del aparecer mismo"43 y, con ello, Henry toma distancia de lo que acostumbra llamar fenomenologías del mundo -incluida la fenomenología de la conciencia intencional husserliana-, las que antes de ocuparse del aparecer propenden más bien hacia lo que aparece, desviando o rehuyendo la cuestión

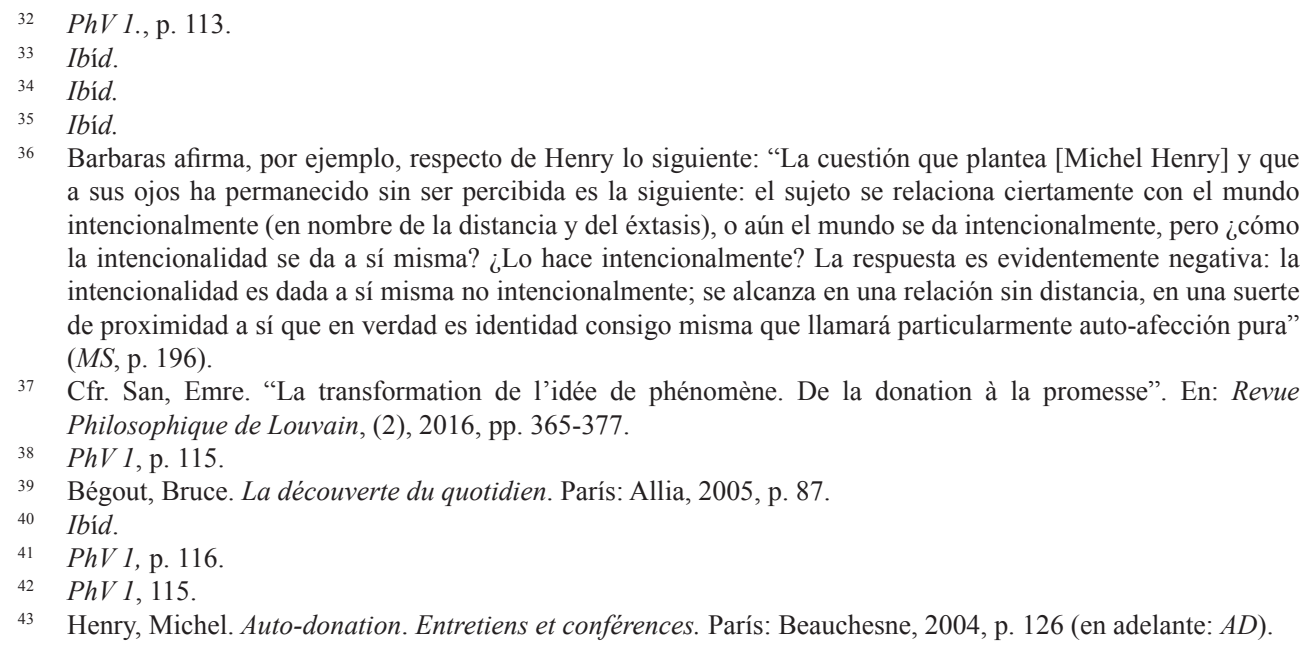
la intencionalidad se da a sí misma? ¿Lo hace intencionalmente? La respuesta es evidentemente negativa: la intencionalidad es dada a sí misma no intencionalmente; se alcanza en una relación sin distancia, en una suerte de proximidad a sí que en verdad es identidad consigo misma que llamará particularmente auto-afección pura" (MS, p. 196).

37 Cfr. San, Emre. "La transformation de l'idée de phénomène. De la donation à la promesse". En: Revue Philosophique de Louvain, (2), 2016, pp. 365-377.

PhV 1, p. 115.

Bégout, Bruce. La découverte du quotidien. París: Allia, 2005, p. 87.

Ibíd.

PhV 1, p. 116 .

PhV 1, 115 .

Henry, Michel. Auto-donation. Entretiens et conférences. París: Beauchesne, 2004, p. 126 (en adelante: AD). 
fenomenológica por excelencia, la donación de la donación, la fenomenalización de la fenomenalidad, en suma, la auto-donación que, a su juicio, es la vida.

Así, la vida es, a juicio de Henry, el fundamento de la fenomenalidad, su esencia orginal, que se sustrae del hacer-ver de la intencionalidad, siendo que en tanto que fundamento no se halla condicionado por ella, ni le debe nada de su aparición al ver intencional. Antes que la vida experiencie el mundo, ésta se experiencia a sí misma, siendo, entonces, el fundamento mismo de la conciencia intencional y del autoaparecer del aparecer. De este modo, la vida será ese puro experienciarse que Henry califica de un "sentirse a sí mismo". Es, por ende, una afectividad trascendental, una inmanencia pura a-relacional a partir de la cual la revelación misma de la vida y lo revelado por ella, la experiencia y el contenido de la experiencia, simplemente se confunden ${ }^{44}$ a diferencia de lo que pasa en la percepción fundada ella misma en la distancia entre el ver y lo visto. Para clarificar aquella confusión sin distancia entre la experiencia y su contenido se puede dar el ejemplo del sufrimiento del sufrimiento que Henry da muchas veces en diversos lugares de su obra. Ciertamente, y Henry no está en desacuerdo con esto, los sentimientos y disposiciones afectivas son intencionales por lo que podemos reconocer sin dificultad que la alegría es alegría de algo, el temor es temor $a$ algo, la tristeza a causa de algo y el dolor también lo es a causa de algo o alguien ${ }^{45}$. Dado esto, habría que afirmar que la esencia de la afectividad no es distinta a la de cualquier hecho psíquico "constituido por la intencionalidad" o "por la trascendencia" ${ }^{4}$. Mas, y a pesar de esta evidencia respecto del despliegue intencional de la afectividad, Henry se interroga si es tal direccionamiento hacia fuera, hacia el objeto mentado o intencionado, lo que determina verdaderamente a la afectividad. Y la respuesta, ciertamente, es ;no! Al contrario: "la afectividad -afirma nuestro autor- es el fundamento universal de todos los fenómenos y los determina a todos originariamente y esencialmente como afectivos. La afectividad de los fenómenos reside en la auto-afección de la trascendencia que despliega el horizonte. No es la captación de aquel, sino la realidad del acto que capta, no es la comprensión

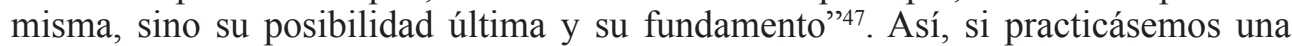
reducción fenomenológica del dolor y con ella nos atuviéramos a lo "doloroso como tal" sin tener que referirlo a una parte del cuerpo objetivo -en tanto que causa de aquel-, con lo que daríamos sería con el "sufrimiento puro" que, a su vez, nos deja saber lo que es el sufrimiento, siendo que lo que se revela aquí no es más que el mismo sufrimiento. De otro modo dicho, solo podemos reconocer el sufrimiento vivido precisamente porque revelándose se muestra a sí mismo, sin tener que referir, de ningún modo, al mundo, ni a ningún "fuera de sí"; es decir, el sufrimiento vivido no conoce distancia ni nada distinto a sí mismo; al contrario de lo que pasa en la vida intencional que está fundada en la distancia que habita entre el ver fenomenológico y lo visto dado en su mentar. Mas, la no-distancia del sufrimiento es al mismo tiempo

44 Cfr. PhV 1, p. 145.

45 Cfr. Henry, Michel. L'essence de la manifestation. París: PUF, 2011, p. 607 (en adelante: EM): "La afectividad no es una cosa, es conciencia y, como tal, conciencia de algo. Ese carácter esencial de la intencionalidad, toda determinación afectiva, al mismo título que no importa que otro hecho psíquico, lo deja ver en ella, en efecto. ¿Qué sería un amor sin objeto, cómo circunscribir un odio que fuera el odio a Pedro o a Pablo, el odio a tal o cual grupo social, por un rasgo de carácter, una actitud vivida precisamente como 'odiable'?’. Sobre este punto, Cfr. Tengelyi, Lásló. L'expérience de la singularité. París: Hermann, 2014, pp. 158-166.

$46 \quad E M$, p. 608.

$47 \quad E M$, p. 608. 
lo que lo hace invisible ${ }^{48}$, inobjetivable, cayendo fuera de la intencionalidad: "Nadie, afirma Henry, ha visto nunca su dolor o su sufrimiento"49. Y ante ello, el filósofo se confronta, por cierto, a aquellas objeciones que podrían resumirse del siguiente modo. ¿Qué pasa en el caso cuando un sufrimiento vivido tiene una causa externa como, por ejemplo, un acontecimiento objetivo como sufrir un accidente automovilístico, una enfermedad grave y dolorosa o un duelo que aqueja profundamente nuestra existencia y nuestras ganas de seguir viviendo? La respuesta del filósofo francés no se deja esperar: "Un acontecimiento, tan dramático como sea, no puede sin embargo producir un sentimiento de sufrimiento sino en un ser constituido trascendentalmente de tal modo que es susceptible de experienciar sentimientos y particularmente aquel -en un ser susceptible de sufrir" ${ }^{50}$.

La afectividad, en tanto que fundamento de la fenomenalidad, es caracterizada como auto-referencialidad, como inmanente, por tanto, sin que ella remita a ninguna cosa que no sea ella misma: el dolor se revela tan solo como tal cuando somos afectados por aquel, sin que indique, ni señale, ni revele nada que no sea él mismo. En suma, la vida se afecta a sí misma sin depender de ningún afuera, de ningún acontecimiento que la sustraiga de sí misma ni la retraiga a sí. Esto indica a su vez, no solo la invisibilidad de la vida -tal como lo decíamos respecto del dolor-, sino también el absurdo que significa para Henry que la vida pueda objetivarse, expresarse o exteriorizarse o, peor aún, "hacerse mundo" 51 . Pero, entonces, ¿qué acceso es posible a la vida si ésta es fundamentalmente invisible? Aquel acceso no es posible por medio del pensamiento ${ }^{52}$, sino por el pathos que le es propio y que revela las diversas modalidades afectivas -desde impresiones simples hasta sentimientos profundos y complejos como la angustia o el tedio- en tanto que experienciadas en sí mismas y que se auto-donan. Henry puede indicar entonces que: "lo que es primero es la experiencia interior de mis impresiones, de mi sufrimiento, de mi deseo, de mi

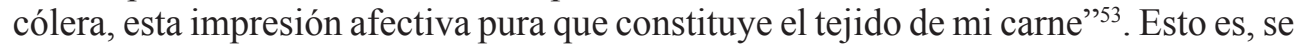
tiene acceso a la vida, en y por la vida en tanto que sentirse a sí misma sin distancia, inmediata a sí. Un acceso a la vida mediante la representación no es posible puesto que la objetiva o, lo que es lo mismo, puesto que la irrealidad noemática ofusca la auto-donación de la vida. La vida no es del orden de lo que aparece, sino del aparecer mismo. De este modo, lo que está en juego aquí es la receptividad-que no lo es de la exterioridad- que constituye la estrucutra originaria de la inmanencia y que demanda pensar una "conciencia sin mundo" 54 , lo que no significa una conciencia solipsista, sino que una antes de ser alienada por lo que ella misma no es; antes, por consiguiente, de su relación extática e intencional con el mundo. $\mathrm{O}$, en palabras de Renaud Barbaras: "en la medida que la intencionalidad no puede dar nada si ella no se da a sí misma esta donación, es necesario reconocer que el segundo orden de fenomenalización, aquel de la distancia o del éxtasis, es ordenado por el primero

48 Henry caracteriza del siguiente modo lo invisible: "lo invisible no es el concepto antitético de la fenomenalidad, es su determinación primera y fundamental [...]. No es solamente la revelación en sí misma de parte a parte, define justamente la naturaleza de esta revelación" (EM, pp. 550-551).

PhV 1, p. 146.

Ibíd., 147.

$A D$, p. 128.

Cfr. $A D$, p. 160.

$A D$, p. 161.

Cfr. EM, p. 293. 
[el de la confusión entre experiencia y contenido]. Tanto decir que la apertura al mundo es sub-tendida por una apertura a sí que, en cuanto a ella, excluye la menor separación, la menor distancia, en suma, se efectúa en lo invisible" ${ }^{\prime 55}$.

Pero esta patética de la vida tiene su fundamento en la oposición que hace Henry entre afectividad, como receptividad de la receptividad, como sentirse a sí misma sin distancia, y la vida intencional que vendría a situarnos ante objetos, siendo que su paradigma es la percepción. Esto debiera conducirnos a pensar un tipo de sí-mismo y de ipseidad que se halla puesto en relación consigo mismo revelando y manifestando la "suficiencia absoluta de su interioridad radical [...]. Porque la afectividad es la esencia de la ipseidad -afirma Henry-, todo sentimiento es, en tanto que tal, como sentimiento de sí, un sentimiento del Sí" ${ }^{56}$. Y justamente es en este punto que el cómo de la manifestación parece ser puesto en riesgo, pues, finalmente, toda tonalidad afectiva, tales como el amor, el odio, la tristeza, la desesperanza, etc., no se dan ellas mismas originariamente en sus notas constitutivas puesto que son reducidas al sentimiento de sí; sus caracteres particulares están fundados en su carácter afectivo, en el "sentirse a sí mismo" que hace posible la identidad del sentimiento y que no es otro que la afectividad en tanto que tal.

De esta manera, los análisis de Henry nos han conducido a las siguientes conclusiones: la afectividad, en tanto que fundante de la ipseidad, del sí-mismo, es la recepctividad de sí que no tolera distancia alguna entre sí y sí mismo, por lo que el contenido de la experiencia, siendo ésta reducida a la inmanencia del sujeto, se confunde con la experiencia misma. Tal como lo hemos dicho anteriormente, Henry se compromete en una suerte de fenología indiferente a lo apareciente, reduciendo la fenomenología al análisis del aparecer mismo como un modo de dar cumplimiento a la necesaria ampliación de la razón ${ }^{57}$. Pero con ello nos parece que Henry sacrifica, en pos del fundamento de la fenomenalización del aparecer, los modos mismos de darse o revelarse de las tonalidades afectivas mismas, reducidas ellas al sentirse a sí mismo propio de la afectividad. La oposición sobre la que opera Henry, entre la donación a distancia de la percepción y la intimidad de la afectividad, parece una oposición que no termina por hacer justicia al sujeto mismo que, sientiéndose a sí, que siendo remitido a sí en la vida afectiva, esta misma afectividad lo dispone, lo entona, hacia el mundo, pero, también, por el mundo. Quisiera, a continuación, examinar otro modo de pensar la experiencia como pathos como es el de Henri Maldiney que, confluyendo con Henry en la necesaria rehabilitación de la experiencia afectiva y en la crítica a la intencionalidad husserliana, se distingue y opone a su vez radicalmente a la marcha del autor de la Essence de la manifestation.

\section{Lo páthico de la existencia}

Como se ha podido apreciar, la afectividad, como fundamento de la fenomenalización del aparecer, parece, coagular el cómo de la manifestación en un modo fundamental de auto-afectividad, invisible como lo es, aunque siendo la fuente misma de la

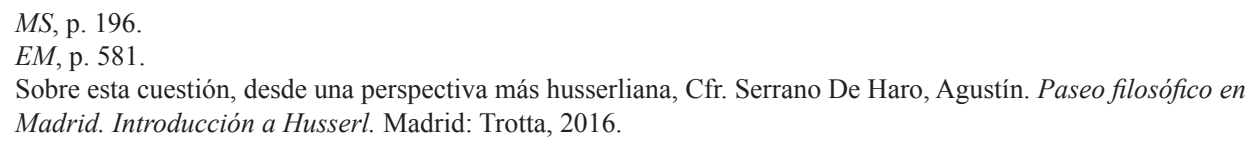


fenomenalidad, no del mundo, sino de la vida. Así, lo que se revela es la revelación misma -el aparecer-. Frente a estos análisis, la obra de Maldiney tiene la virtud de pensar el fundamento afectivo de la ipseidad, ya no en tanto que inmanencia radical y autoafección, sino como apertura a la trascendencia. Y por ello, lo que está en juego en la obra de este autor no es un "sentirse a sí", como en el caso de Henry, sino un resentir, siendo que aquel pone en evidencia un pathos capaz de revelar una brecha o herida en el existente, un riesgo que es propio del mantenerse abierto a lo otro. En suma, de lo que se trata no es, por ejemplo, del dolor que doliendo se anuncia a sí mismo y nada más que a sí (impresión pura, auto-afección, sentirse), siendo que su superación, la de toda tonalidad afectiva a juicio de Henry, es el volver a sí, el manifestarse a sí, esto es, el mantenerse en sí como tal. Por el contrario, la filosofía de lo páthico de Maldiney compromete una fenomenología de la receptividad, esto es, de la actividad propia -y que es su ocasión- de la pasividad sin la cual no se recibe ni acoge lo otro. Mientras que la obra de Henry es indiferente a la experiencia de la alteridad, la de Henri Maldiney se halla toda ella volcada hacia un pensamiento del encuentro ${ }^{58}$ y de la recepción que aquel implica y que, bajo ningún respecto, puede ser sostenido por una filosofía de la sola pasividad, incluso si ésta toma la forma levinasiana de una "pasividad más pasiva que toda pasividad".

¿Cómo comprender este encuentro entre el sujeto y lo otro? ¿Qué tipo de receptividad está en obra? Si se trata de receptividad, bien podría anunciarse la vía intencional de la fenomenología como el ámbito propicio para dilucidar esta cuestión, en cuanto ésta es una correlación donde hay implicado un sujeto que se dirige y vuelve hacia un objeto que, a su vez, se da y manifiesta en el seno de la experiencia misma. Así, por ejemplo, Husserl se refiere ciertamente al fundamento afectivo del ego en tanto que implica una relación motivada, fundada y despertada por el interés que suscitan los objetos. De este modo, afirma el autor: "la vida del alma es despertada, es decir que el yo es despertado, y es así en tanto que realiza las funciones egoícas específicas según un modo actual, por tanto en cuanto realiza actualmente un 'yo percibo', es decir, yo estoy volcado hacia algo objetivo por la intuición, por la contemplación y ocupado con él, del mismo modo, yo me recuerdo, yo soy absorbido en la contemplación de lo rememorado, del mismo modo, yo comparo y distingo, comparando, reconozco que eso percibido ahí y allá son del mismo género; o bien soy conducido a amar, a estimar, a venerar a una persona que yo me represento, o me vuelvo contra ella con odio y desprecio, realizo un acto de mentar, sopesando los medios, me decido y actúo" ${ }^{9}$. Mas la cuestión es, a juicio de Maldiney, si la receptividad comprometida aquí, esto es, que manifiesta la relación entre sujeto, ego, y objetos intencionales, es el suelo originario desde el cual pensar el encuentro con las cosas. Esto, pues, y tal como parece indicarlo Husserl mismo en los escritos sobre las síntesis pasivas, incluso si se trata de objetos dados conforme a una fuerza afectiva atrayente y excitante que opera en el ego una conversión atencional, éste, el ego, no abandona su poder de constitución por lo que sigue siendo sujeto de sus actos, aquel que los realiza, incluso si es atraído hacia los

58 Al respecto Maldiney dice: "Lo real no es lo objetivo: es, no la objetivación, sino la comunicación que constituye el momento de realidad. El encuentro es eso en que lo real tiene lugar" (L'art,l'éclaire de l'être. París: Cerf, 2012, p. 181). Y también: "Un encuentro verdadero no cumple la espera. La sor-prende; y del mismo modo, la trans-forma e incluso, en el instante que la colma, la crea" (ibid., p. 286).

59 Husserl, Edmund. De la synthèse passive. Logique trascndantale et constitutions originaires. Grenoble: Jérôme Millon, 1998, p. 36. 
objetos y motivado por ellos. Así, por un lado, el ego no deja de ser constituyente, ni tampoco abandona nunca el ámbito de la objetidad. Sin negar la pertinencia de estos análisis, se puede sospechar, tal como lo hace Maldiney, que la receptividad aquí en juego es segunda y derivada. Debe ser posible comprender un encuentro primario y originario que no nos ponga ante objetos - por mucho que estos sean fenómenos y no objetos empíricos en sí-, sino que nos permita dar cuenta del primer encuentro con las cosas mismas, sin que éstas sean reducidas a entes u objetos o, incluso, útiles ${ }^{60}$. Y en efecto, no hacemos la experiencia de un ente sin comprometer un acto filosófico delimitante, ni la de un objeto que implica una operación de reducción de la cosa -el trozo de cera por ejemplo- a sus caracteres más simples, necesarios y constantes; así, también, no hacemos la experiencia de un fenómeno, en el sentido fenomenológico, sin la epojé, la reducción, etc. En cada uno de estos casos no solo es preciso que el sujeto -filosofante, científico, etc. - se disponga y vuelva intencionalmente hacia las cosas, sino que se esfuerce en ganar lucidez sobre los actos mismos de constitución. Pues, precisamente, tal como lo reconoce Marion, "el objeto no se regula sobre la verdad de su existencia (ni de su esencia), sino por la puesta en orden por nosotros en vista a producir la evidencia para nosotros" "61, por lo que, manteniéndonos en el caso del objeto, lo que éste revela es más bien "el punto de vista de nuestra mirada (spectare, poder de intuición)" 62 antes que al objeto mismo; o, en otras palabras, el objeto siempre dice más de la mirada que lo ha constituido que de él mismo.

Entonces, ¿es posible pensar una receptividad que, antes de ponernos ante objetos -entes, útiles, etc. -, que son siempre obra de constitución y que requieren para su manifestación de un tipo de operación y de mediación, nos permita dar cuenta de las cosas mismas liberadas, esta vez, de todo a priori o condición para su manifestación? La vía tomada por Maldiney es hostil, por cierto, a la de la intencionalidad que no deja de situarnos ante objetos y que cuenta siempre con un horizonte de objetividad que le es irrenunciable. Mas, tal vez, y siguiendo en esto a Erwin Straus, sea el sentir ${ }^{63}$, antes que el percibir, aquel que comprometa una receptividad nointencional, no objetivante, $\mathrm{y}$, por ello mismo, verdaderamente expuesta en cuanto receptividad. Así, la receptividad es pensada como la apertura al acontecimiento ${ }^{64}$, lo que implica que la receptividad es tal ante lo que no puede recibir, si por recibir se entiende una normatividad a partir de la cual la cosa puede darse, sin la cual no puede manifestarse. Pues, parece cierto que el fenómeno es normado, siendo el esquema intencional la norma de su manifiestación y cumplimiento ${ }^{65}$. Mas, el acontecimiento es precisamente lo que se manifiesta fuera de norma o más allá de

60 Jacquet, Frédéric. La Transpassibilité et l'événement, op. cit., 13: "El sentir es el momento páthico al cual se aplica la palabra de Esquilo de 'una aprendizaje por la prueba', que designa el encuentro que hacemos de las cosas más acá de su objetivación, antes que ellas sean transformadas en objetos susceptibles de identificación”.

${ }_{61}$ Marion, Jean-Luc. Reprise du donné. París: PUF, 2016, p. 162.

62 Ibíd.

${ }^{63}$ Al respecto, Maldiney indica que: "Pues el sentir tiene él mismo su verdad. La vista, el oido, los otros sentidos no nos procuran solamente impresiones sensibles que tengan valor representativo. Pues esos mismos colores y esos mismos sondios que nos introducen en las objetos disponen de nuestra Stimmung y de nuestro comportamiento, según leyes determinadas que dan el tono a nuestro Umwelt y ponen, por así decir, nuestra receptividad en situación. El yo del sentir es una receptividad abierta y realizada [...]. Se puede hablar del ser con... del sentir como un ser-con-el-mundo más que un ser-en-el-mundo" (Maldiney, Henri. Regard parole espace. Paris: Cerf, 2012, p. 189.

${ }_{64}$ Cfr. Maldiney, Henri. Penser l'homme et la folie. Grenoble: Millon, 2007, pp. 307-308 (en adelante: PHF).

65 Cfr. Benoist, Jocely. Logique du phénomène, op. cit.. 
toda norma. Éste, el acontecimiento, no se deja inscribir en un contexto previo de sentido pues él mismo aporta su propio sentido; es anárquico, es decir, no puede ser datable pues su advenir mismo no nos es contemporáneo ni tiene una causa u origen que pueda ser reconocida. Por todo ello, el acontecimiento parece ser, precisamente, lo que - a contrario de lo dicho por Maldiney- no se puede recibir, pues no se deja normar, i.e., no condiciona su manifestación a otras condiciones -subjetivas- que no dependan de él. Es imprevisible por lo que no solo no depende del sujeto para arribar, sino que este último no puede siquiera prepararse para su advenimiento. Así, entonces, ¿en qué sentido puede afirmar Maldiney que solo el acontecimiento puede ser recibido cuando todo indica que no es así, que éste ofusca toda posibilidad de receptividad? Y esto, en cuanto hemos dicho, siguiendo al filósofo de Lyon, que la receptividad es la actividad de la pasividad, por lo que se puede suponer una participación de parte del sujeto que consiste, precisamente, en un hacer por el cual se recibe, en este caso, el acontecimiento. Y más aún, ¿inscribir la actividad en la receptividad no es mantenerse en el ámbito de la intencionalidad que es la vía a la que Maldiney ha renunciado? Precisamente, el acontecimiento, en tanto que imprevisible, es aquel fenómeno que se da en sí mismo, sin condición subjetiva previa, y que dándose, vale decir, arribándole al sujeto, se hace él mismo recibir. Maldiney llamará transpasibilidad ${ }^{66}$ a esta aptitud propia del existente humano para recibir lo que no cabe ser esperado, siendo entonces una apertura no intencional y "que no es del orden del proyecto" pasible de nada que pueda hacerse anunciar como real o posible. Es una apertura sin propósito y sin diseño a aquello de lo que no somos a priori pasibles. Ella es lo contrario del cuidado: 'La rosa es sin por qué, ella florece porque florece, no se inquieta de sí misma'. Ella existe por nada. Por la nada que la libera de todo vínculo previo al ente y que significa en ella que su existencia es originaria"68.

Siendo que la receptividad lo es de lo que no puede ser esperado, el acontecimiento o, tal como el propio Maldiney lo dice, la realidad, no puede tratarse aquí de la vida en su auto-manifestación ni del viviente, sino que de la existencia y del existente. La exposición a lo inesperado solo cabe de aquel que se existe a sí mismo y se mantiene como el ahi de su apertura y no de un viviente incapaz, como en el caso de Henry, de salir de sí. Maldiney compromete aquí una análisis del existir que, sin embargo, no depende del cuidado (Sorge) que articula Befindlichkeit y Verstehen; por el contrario, nuestro autor da con una antilógica del cuidado, pues siendo que el existente se tiene a sí fuera de sí, aquel estar tendido, estar dirigido y lanzado significa estar verdaderamente aventurado y expuesto hacia lo inimaginable. De este

66 El 05 de mayo de 1986, Maldiney le escribe a Roland Kuhn una carta en la que le indica que lo transpasible es "irreductible a todo a priori de la pasividad", e inmediatamente después afirma: "Y la última filosofía de Heidegger comienza a hacer estado de ello. Sacrifica la idea de horizonte y de proyecto. Y es aquí que toma sentido la Empfindung" (Maldiney, Henri \& Kuhn, Roland. Rencontre. Begegnung. Au péril d'exister (19542004). Würzburg: Königshausen \& Neumann, 2017, p. 522).

67 PHF, p. 114.

${ }_{68} P H F$, p. 306. Al respecto, Jacquet dice: "La lección de la filosofía maldiniana es enseñarnos a pensar de modo no metafísico suspendiendo el uso del principio de razón suficiente; así, el acontecimiento surge de Nada, escapa al entrelazamiento de las causas y efectos ('La causalidad no toca al ser'). Se trata menos de renunciar a la ontología que de sustraerla de la óptica metafísica, es decir de un pensamiento del fundamento, de liberar así a la realidad del imperio de la objetividad en provecho de una fenomenología de la aparición 'anterior a toda distinción del proceso y del substrato'. La realidad es lo que excede toda aprehensión" (Jacquet, Frédéric. $L a$ Transpassibilité et l'événement, op. cit., p. 33). 
modo, Maldiney puede afirmar entonces que: "El ser-ahí no existe sino deviniendo contemporáneo de su origen en la dirección de su salida. La existencia se abre ella misma abriendo la dimensión de lo posible, de lo único posible auténtico que no falla nunca en su posibilidad porque es posibilitación. El existente no es tal más que al posibilitarse [...] Existe haciendo del aquí al cual está arrojado su ahí, a título absolutamente propio, es decir, cada vez absolutamente mío -eso por lo que el ente que es yo deviene el ente que yo soy" 69 .

Así afirma también: "Ahí donde yo veo yo soy. Ahí donde yo soy yo veo"70. Se comprende entonces que la transpasibilidad no puede ser entendida como una relación con lo posible, ni tampoco como posibilitación. Por el contrario, la transpasibilidad señala una imposibilitación fundamental del existente, pues es la apertura a lo imposible de sí, esto es, a lo que adviene como acontecimiento. No somos pasibles a lo posible, sino que a lo imposible. Es esto último la pura fenomenalidad a la que se está abierto pasiblemente. "El aparecer, el phainesthai -afirma Maldiney- no tiene más acá. Él aporta y lleva consigo su comienzo. Lo que aparece y se descubre por sí mismo a partir de nada"71. De este modo, el aparecer se impone él mismo por sus propios medios y abre adviniendo al existente que hace su experiencia; o, lo que es lo mismo, vuelve al existente capaz de recibirlo. La transpasibilidad, por tanto, es una capacidad que consiste en el poder de recibir lo que no podía saberse de antemano como aquello por recibir, pero tampoco, y por lo mismo, aquello de lo que no podía anticiparse los modos de recibirlo. No se trata, por consiguiente, de una capacidad cuya efectuación y posibilitación dependa del existente, sino que ésta misma es abierta y constituida por lo que le adviene. Y en este sentido, la capacidad de la pasividad, que es la receptividad, se comprende pudiendo lo que puede solo pudiéndolo, sin que antes fuera posible que ésta se desplegase como "tal", como ésa y no como aquella capacidad, pues su devenir y efectuación depende del arribo de lo que no era posible esperar; el acontecimiento. Se puede apreciar la diferencia radical con Henry. Para este autor la capacidad requiere para poder desplegarse de un momento fundante tal como el de poder revelarse a sí misma por sí misma: "Una fuerza absoluta, una causalidad eficiente, un poder de su efectividad, en la realidad y la actualidad de su ejercicio, de lo que es y de lo que hace, no puede ser en el medio de la exterioridad, no puede ser exterior a sí y como exterior a sí, no puede estar separada de sí, no puede ser extraña para sí misma. Eso significa -continúa Henry- que a todo poder verdadero un primer poder es dado, aquel precisamente de ser él mismo, de apropiarse de él mismo, de coincidir consigo en una suerte de coherencia primera que rechaza toda especie de distancia y de separación, en suma, en la inmanencia de su interioridad radical"72.

Mientras que el poder de ser sí está fundado en Henry -así como sus condiciones de efectuación y de posibilitación-en un sentirse a sí radical e inmanente, sin distancia ni diferencia, la capacidad en Maldiney es abierta y posibilitada por lo inesperado que adviniendo expone al existente abriéndolo a lo imposible o inimaginable. Esto es, toda capacidad tiene su fundamento en la receptividad que sin saberse ella misma de qué es capaz y cómo lo es, abre al existente a lo imposible, antes que a lo posible.

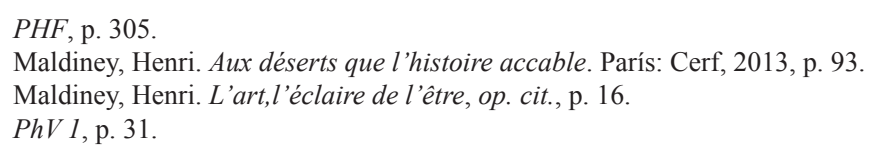


Por lo que el poder de acoger y recibir implica a su vez el poder de sufrir o de padecer lo advenido que es precisamente lo transpasible. La pasibilidad es una capacidad propia del existente de padecer la crisis que abre el acontecimiento, el que por lo demás no acontece sino en el advenimiento del existente. "Un acontecimiento es una ruptura en la trama del mundo y su aparecer se sustrae al transporte de los efectos y de las causas. Del mismo modo, el presente del aparecer es una desgarradura en la trama temporal" ${ }^{13} ; \mathrm{y}$, de este modo, se puede decir que el acontecimiento reconfigura el todo de los posibles del existente, así como hace época y abre un hiato y una crisis en la historia de aquel, transformando y estremeciendo en sus poderes al existente. Esto implica, a su vez, pensar la experiencia en su radicalidad. Hacer la experiencia de lo que se da, de lo real, no puede significar "tener eso real delante de sí -como ob-jeto" "74. Por el contrario, tal como lo recuerda Maldiney, la raíz indoeuropea per que se halla en el vocablo griego empeiría, experiencia, etc., y remite a una travesía que se hace, a una aventura que se prosigue. Así, Maldiney afirma que: "Nuestra primera relación con el mundo se expresa por ese 'a través'. El mundo que se anuncia en la raíz 'per' es el de la experiencia: empeiría, experientia, Erfahrung. La experiencia en la que nos encontramos y aprendemos las cosas es una travesía. Pero entendamos bien: una travesía humana"75. Esto es, el hacer experiencia, que remite al tò páthei máthos de Esquilo ${ }^{76}$, es aquel aprendizaje que se obtiene del padecer y del sufrimiento, sin el cual las cosas no podrían verdaderamente ser comprendidas ni primeramente sentidas. El surgir mismo de la cosa que nos sorprende y que viene a nuestro encuentro de modo inesperado radica en el sentir que: "porta consigo el instante-lugar de su aparición sin referencia posible [...]. El acto puro del aparecer, el phainesthai es el ¡Ah! universal, la exclamación fundadora que desgarra el catálogo razonado de las apariencias y el código de las razones. Aquel que se despierta en el mundo a la luz de la desgarradura es el ahi de todo lo que tiene lugar"77.

Si las cosas aparecen y se presentan no lo hacen en tanto que fenómenos intramundanos, sino en cuanto son sentidas, siendo el sentir "el lugar originario del aparecer"78. Se trata de un sentir pre-perceptivo que está más acá de toda percepción que en cuanto tal no deja de ser intencional y por consiguiente objetivante. La experiencia del sentir originario es una que abre al existente a una receptividad pura y no objetiva, que no depende en nada de un ser capaz de proyectarse y que no cuenta con el movimiento intencional y atencional -i.e. anticipatorio- propio de la percepción. Por el contrario, abre al existente a la experiencia misma de la nada -así la angustia, por ejemplo ${ }^{79}$. Dicho de otro modo, el sentir no está vuelto a nada que pueda ser anticipable, imaginable y anunciado previamente puesto que en él "todo está ahí para mí y es solamente que está ahí para mí que es ahí en tanto que tal”"80.

PHF, p. 304.

74 Grosos, "Philippe. "L'expérience du rien dans la philosophie d'Henri Maldiney”. En: Meitinger, Serge (ed.). Henri Maldiney, une phénoménologie à l'impossible. Puteaux: Le Cercle Herméneutique, 2002, p. 147.

75 Maldiney, Henri. L'art, l'éclaire de l'être, op. cit., p. 232.

76 Cfr. Jacquet, Frédéric. La transpassibilité et l'événement. Essai sur la philosophie de Maldiney. Paris: Garnier, 2017, pp. 13-16.

77 Maldiney, Henri. Aux déserts que l'histoire accable, op. cit., p. 93.

78 Barbaras, Renaud. “L'essence de la réceptivité: trasnpassibilité ou désir?”. En: VV. AA. Maldiney, une singulière présence. París: Belles Lettres, 2014, p. 19.

79 Cfr. Grosos, Philippe, art. cit., pp. 143-165.

80 Straus, Erwin. Du sens des sens. Contribution à l'étude des fondements de la psychologie. Grenoble: Millon, 2000, p. 503. 
Mas acá de la objetivación, el sentir es un "vivir-con inmediato" pre-conceptual, pre-judicativo que revela la participación primordial del existente en el mundo; es aquella presencia $a_{\text {... }}$ que se deja sentir abrazando del todo al existente conforme a múltiples tonalidades afectivas por las que éste -el existente- es tomado. En palabras de Claude Romano el sentir es "el lugar de significaciones adherentes a las cosas, conocidas antes de ser reconocidas, el lugar de un 'saber' indiviso, global, no analítico, no temático y sin embargo consistente"81. Así, el sentir es el modo cómo las cosas se donan, antes de su objetivación, mas fuera del ámbito de la vida intencional. Nos hallamos entonces con una fenomenología que no renuncia al retorno a las cosas mismas, incluso si este volver a ellas implique dar cuenta de un aparecer puro antes de la tematización de las cosas en objetos; y esto, a diferencia de la filosofía de Henry que movido por la búsqueda de la descripción de un aparecer puro resigna el retorno a las cosas mismas.

\section{La acontecialidad y el encuentro que exponen el dónde de la manifestación}

Hasta aquí hemos avanzado desde una fenomenología de la patética de la vida a una del pathos de la existencia, y con ello hemos buscado dar cuenta, de modo parcial ciertamente, de un giro dado en la fenomenología hacia la afectividad y receptividad como modos de cumplimiento tanto de la consigna husserliana de volver a las cosas mismas, así como de la exigencia fenomenológica de ampliar la razón hacia lo predado, lo ante-predicativo, etc. Como expresión de realización de esta doble consigna hemos examinado las propuestas fenomenológicas de Henry y Maldiney. Ambos autores se han situado en una vía no-intencional y han abandonado la fenomenología en su versión idealista, con el fin, precisamente, de dar con las cosas mismas en el momento mismo de su emergencia: la auto-afección de la vida siendo para el primero la fuente misma de la fenomenalidad pura, i.e. el puro aparecer; la transpasibilidad como receptividad de lo inesperable, más acá por tanto del proyecto y del cuidado para el segundo. En el primer caso, la fenomenología de la vida clausura al viviente a una experiencia continua de sí intentando situarse a un nivel originario antes del momento extático que implica el encuentro con el mundo, siendo lo yectivo fuente de encubrimiento del aparecer mismo antes que su revelador. Pero Maldiney, también en busca del momento originario del aparecer, el "iAh! de las cosas”, no se compromete ni con la vía de la inmanencia radical de Henry, ni, a pesar de las apariencias, con la vía de una fenomenología yectiva. Es cierto que nuestro autor destaca el momento extático del existente, mas aquel "tenerse fuera de sí", aquel existir, no está abierto hacia los posibles. Bajo ese respecto habría que decir más bien que el existente aquí en juego está en una relación acontecial, antes que existencial, con el mundo y las cosas en su advenimiento. O, habría que decir, que la existencia como ahi apertural consiste en su capacidad para el advenimiento de sí por lo otro que acontece y, que en cuanto tal, adviene siempre de modo inesperado a espaldas del existente, no siendo nunca contemporáneo su arribo del advenir del sujeto. No es por tanto el carácter yectivo del existir, sino la disponibilidad para el encuentro de lo otro que permite comprender mejor la existencia en su fundamento afectivo. Encuentro, ciertamente, no delimitado por el cuidado, sino por el advenir y la sorpresa, por la experiencia

${ }^{81}$ Romano, Claude. Le chant de la vie. París: Gallimard, 2005, p. 46. 
de la primera vez a la que nos expone el acontecimiento. Es el encontrarse abierto, expuesto y lanzado hacia lo imposible el a priori de la manifestación. Es el fenómeno -aquí tomado en su carácter acontecial- aquel que se impone al existente y lo expone llamándolo, exhortándolo, a la realización de sí que, antes del encuentro, era inimaginable para sí. Y con ello, la fenomenología de Maldiney, a diferencia de la de Henry, da acceso a una subjetividad abierta y en relación con lo otro, con la alteridad, siendo que su forma radical es la de no poder ser tomada, tematizada y apresada por la objetividad.

La cuestión del encuentro nos sitúa ante la pregunta acerca del dónde, esto es, del surgimiento mismo de las cosas y de su manifestación. En la experiencia de un encuentro es el fenómeno el que toma la iniciativa antes que el sujeto que lo confronta. La cosa, en su advenir, se da imponiéndose de tal modo que quien la encuentra no sale indemne del arribo de ésta. Lo que aquí se vuelve objeto de atención es el aparecer mismo, el surgir de lo dado. Mas, esto implica un desplazamiento de la cuestión fenomenológica por excelencia que va de la pregunta por el cómo de la manifestación de la cosa hacia la cuestión del dónde de su surgimiento. No se trata de un abandono puesto que es la última pregunta aquella que permite contestar verdaderamente la primera. Así, el dónde de la manifestación permite revelar precisamente el carácter acontecial de lo dado, el hecho de que éste se done según la sorpresa, la primera vez y lo inesperable, en tanto que pone en evidencia que el acontecimiento -la cosa como advenir- no se da sin que ponga al desnudo al existente que lo recibe y lo que para éste implica acogerlo. $\mathrm{Y}$ en este sentido, la cuestión dónde releva también el hecho de que lo que está en juego aquí es el encuentro mismo del que el existente es capaz -siendo aquí que la capacidad debe comprenderse, antes que como iniciativa de un agente, como una disposición del existente a ser abierto por lo otro que viene, a hacerle un espacio, a dilatarse en pos del encuentro con la alteridad-y cuya iniciativa primera la tiene aquello que llega y se hace espacio.

La pregunta dónde revela que lo que se da en el encuentro no surge simplemente como una cosa del mundo, siendo por supuesto una cosa del mundo, ni tampoco surge propiamente en el sujeto que se halla sorprendido en el encuentro ${ }^{82}$. Mas bien, aquello que se encuentra -y que nos encuentra y nos persigue o acosa-, da cuenta de que, por una parte, es una cosa del mundo, y por otra que "el mundo es en ella". Su aparición, su mostrarse y hacerse presente, abre precisamente el mundo como un brecha para el existente. De este modo, el fenómeno se impone en la medida que no se deja reducir a ser tomado como un objeto intencional ni como un fenómeno intramundano. Por el contrario, se dona como un acontecimiento que, distinguiéndose del hecho cotidiano o intramundano, es recibido como un hecho original, es decir, como un Urphänomen que en su advenimiento nos porta un sentido nuevo, una interrogación, un problema que hace época en la historia del existente; reconfigura su mundo y marca un antes y un después en términos epocales. Mas, lo que es interesante de todo esto es que la experiencia del encuentro se reconoce ella misma excedida por lo advenido. No es lo encontrado en cuanto cosa material, ni en tanto útil o, incluso, ni siquiera en cuanto aquella obra de arte que se presta a una exégesis delimitante de su génesis histórico-

82 Siendo que lo propio del encuentro, en palabras de van Kerchoven es que éste "es precisamente sin espera [...], es sorpresa" (Van Kerchoven, Guy. De la rencontre. París: Hermann, 2012, p. 19), siendo que "su fenomenalidad es salvaje, fuera de los registros de las anticipaciones de nuestras actitudes y de los acomodos cuán rápidos de nuestros sentidos" (Ibid., p. 20). Del mismo autor, Cfr. Le présent de la rencontré. París: Hermann, 2014, pp. 29-63. 
factual, sino solo en tanto que evento o hecho original cuya recepción pone en juego a quien acoge el sentido innovante y problematizante que éste propone.

Lo que está en juego, entonces, es el hecho de que el encuentro hace del existente, un aventurado por tenerse, precisamente, fuera de sí. De este modo, la experiencia que se hace conlleva una recomprensión de lo que recibir y acoger significan. La recepción que compromete aquella experiencia en tanto que prueba (épreuve) es radical en la medida que supone una exposición tal a lo adventicio de las cosas que no se puede decir que aquella soporte mínimamente ninguna previsión ni preparación alguna ante lo que se da a recibir. Y, de este modo, quien hace la experiencia de lo dado en su dimensión acontecial no puede separarse ni distinguirse de aquello, hallándose totalmente hundido e implicado en ello en cuanto lo advenido no es solo la cosa misma -si acaso ésta es reducida a un objeto cualquiera-, sino la cosa en tanto que aquella comprende -reúne entonces- al evento advenido en el existente, abriendo un mundo y una historia, y al existente advenido él mismo en el mundo que le es dado de un modo nuevo. Aquí, se puede afirmar, la cosa llama de otro modo, pues su llamado compromete el todo del existir personal, implicándolo en el advenir de lo dado acontecial y de sí mismo como aventurado, esto es, como quedando expuesto a posibilidades verdaderamente inéditas que son, en cuanto tales, precisamente aquellas que no se pueden antes de su encuentro. Es solo siendo confrontado con el inédito advenir de la cosa que se es llamado a la concretización de una llamada recibida y no podida antes de ser acogida.

\section{Referencias bibliográficas}

Barbaras, Renaud. “L'essence de la réceptivité: trasnpassibilité ou désir?”. En: VV. AA. Maldiney, une singulière présence. París: Belles Lettres, 2014, pp. 17-31.

Barbaras, Renaud. Métaphysique du sentiment. París: Cerf, 2016.

Bégout, Bruce. La découverte du quotidien. París: Allia, 2005.

Benoist, Jocelyn. Logique du phénomène. París: Hermann, 2016.

Capelle-Dumont, Philippe. "Après Merleau-Ponty, que devient la phénoménologie française?”. En: Zarka, Yves Charles (ed.). La philosophie en France aujourd 'hui. París: PUF, 2015, pp. 189-210.

Depraz, Natalie. Le phénomène. París: Bréal, 2014.

Gondek, Hans-Dieter y Tengelyi, László. Neue Phänomenologie in Frankreich. Berlin: Suhrkamp, 2011.

Grosos, Philippe. "L'expérience du rien dans la philosophie d'Henri Maldiney". En: Meitinger, Serge (ed.). Henri Maldiney, une phénoménologie à l'impossible. Puteaux: Le Cercle Herméneutique, 2002, pp. 143-165.

Henry, Michel. Phénoménologie materielle. París: PUF, 1990.

Henry, Michel. Phénoménologie de la vie I. De la phénoménologie. París: PUF, 2003.

Henry, Michel. Auto-donation. Entretiens et conférences. París: Beauchesne, 2004.

Henry, Michel. L'essence de la manifestation. París: PUF, 2011.

Husserl, Edmund. Investigaciones lógicas tomo II. Madrid: Alianza Editorial, 1985.

Husserl, Edmund. De la synthèse passive. Logique trascendantale et constitutions originaires. Grenoble: Jérôme Millon, 1998.

Husserl, Edmund. La crisis de las ciencias europeas y la fenomenología trascendental. Buenos Aires: Prometeo, 2008. 
Husserl, Edmund. Ideas relativas a una fenomenología pura y una filosofía fenomenológica, Libro primero: Introducción general a la fenomenología pura. México: UNAM / FCE, 2013.

Jacquet, Frédéric. La transpassibilité et l'événement. Essai sur la philosophie de Maldiney. Paris: Garnier, 2017.

Kerchoven, Guy van. De la rencontre. París: Hermann, 2012.

Kerchoven, Guy van. Le présent de la rencontre. París: Hermann, 2014.

Maldiney, Henri. Penser l'homme et la folie. Grenoble: Millon, 2007.

Maldiney, Henri. L'art,l'éclaire de l'être. París: Cerf. 2012.

Maldiney, Henri. Regard parole espace. Paris: Cerf, 2012.

Maldiney, Henri. Aux déserts que l'histoire accable. París: Cerf, 2013.

Maldiney, Henri \& Kuhn, Roland. Rencontre. Begegnung. Au péril d'exister (1954-2004). Würzburg: Königshausen \& Neumann, 2017.

Marion, Jean-Luc. "Un moment français de la phénoménologie". Rue Descartes, Phénoménologies françaises, (35), 2002, pp. 9-13.

Marion, Jean-Luc. Étant donné. París: PUF, 2005.

Marion, Jean-Luc. “Jean-Luc Marion. Entretien avec Paul Audi”. En: Zarka, Yves Charles (ed.). La philosophie en France aujourd 'hui. París: PUF, 2015, pp. 465-474.

Marion, Jean-Luc. Reprise du donné. París: PUF, 2016.

Mena, Patricio. “El fenómeno de la apelación”. En: Revista Co-herencia, (23), 2015, pp. 106-137.

Perreau, Laurent. “Le sens de l'apparaître. Le phénomène et le phénoménologique chez Husserl”. En: Perreau, Laurent (ed.). Le phénomène. París: Vrin, 2014.

Ricoeur, Paul. À l'école de la phénoménologie. París: Vrin, 1986.

Romano, Claude. L'événement et le monde. París: PUF, 1998.

Romano, Claude. L'événement et le temps. París: PUF, 1999.

Romano, Claude. Le chant de la vie. París: Gallimard, 2005.

Romano, Claude. Au coeur de la raison: la phénoménologie. París: Gallimard, 2010.

San, Emre. "La transformation de l'idée de phénomène. De la donation à la promesse". En: Revue Philosophique de Louvain, (2), 2016, pp. 365-377.

Schmitz, Hermann. Brève introduction à la nouvelle phénoménologie. París: Le Cercle Herméneutique, 2016.

Schnell, Alexander. Qu'est-ce que le phénomène. París: Vrin, 2014.

Sebbah, François-David. "Nouvelle phénoménologie et post-phénoménologie”. En: Sommer, Christian (ed.). Nouvelles phénoménologies en France. París: Hermann, 2014, pp. 149158.

Serban, Claudia. 'La 'Nouvelle phénoménologie en France' et les événements de sens (Sinnereignisse). Un prolongement de la lecture de László Tengelyi”. En: Cabestan, Philippe (ed.). Claude Romano. La raison et l'événement. París: Le Cercle Herméneutique, 2016, pp. 31-45.

Serrano De Haro, Agustín. Paseo filosófico en Madrid. Introducción a Husserl. Madrid: Trotta, 2016.

Sommer, Christian (ed.). Nouvelles phénoménologies en France. París: Hermann, 2014.

Straus, Erwin. Du sens des sens. Contribution à l'étude des fondements de la psychologie. Grenoble: Millon, 2000.

Tengelyi, Lásló. L'expérience de la singularité. París: Hermann, 2014.

Vallé, Marc-Antoine. "Par-delà le príncipe de raison: la phénoménologie de l'événement chez Jean-Luc Marion et Claude Romano". En: Cabestan, Philippe (ed.). Claude Romano. La 
raison et l'événement. París: Le Cercle Herméneutique, 2016, pp. 17-29.

Waldenfels, Bernhard. Exploraciones fenomenológicas acerca de lo extraño. Madrid: Anthropos / Siglo XXI editores, 2015. 